\title{
Liberating microfossils from indurated carbonates: comparison of three disaggregation methods
}

\author{
Charlotte Beasley ${ }^{1}$, Daniel B. Parvaz ${ }^{2,3}$, Laura Cotton ${ }^{4}$, and Kate Littler ${ }^{1,5}$ \\ ${ }^{1}$ Camborne School of Mines, University of Exeter, Penryn Campus, Penryn, Cornwall, TR10 9FE, UK \\ ${ }^{2}$ Lightning Machines, 2nd Floor, Grove House, 774-780 Wilmslow Road, \\ Didsbury, Greater Manchester, M20 2DR, UK \\ ${ }^{3}$ SELFRAG AG, Biberenzelgi 18, 3210 Kerzers, Switzerland \\ ${ }^{4}$ School of Environment, Geography and Geosciences, University of Portsmouth, \\ Burnaby Building, Burnaby Road, Portsmouth, Hampshire, PO1 3QL, UK \\ ${ }^{5}$ Environment and Sustainability Institute, University of Exeter, \\ Penryn Campus, Penryn, Cornwall, TR10 9FE, UK \\ Correspondence: Charlotte Beasley (c.beasley@exeter.ac.uk)
}

Received: 11 June 2020 - Revised: 7 August 2020 - Accepted: 20 August 2020 - Published: 9 October 2020

\begin{abstract}
Three disaggregation methods, i.e. Calgon, acetic acid and electric pulse fragmentation (EPF), have been applied to a range of heavily lithified, carbonate-rich sedimentary rock samples of Paleogene age. Samples are predominantly from the carbonate-rich, shallow water domain $(<250 \mathrm{~m}$ palaeo-water depth) of Tanzania, Malta and the United Arab Emirates (Paleogene Tethys Ocean). The effectiveness and efficiency of each method has been compared, in addition to the preservation of the resultant liberated microfossil material (primarily larger foraminifera; LF). Of the three methods, the most efficient and effective was EPF, which liberated the largest number of LF in a very short processing time and resulted in the best preservation. Samples with calcitic, silicic, and clay matrices and cements were successfully disaggregated using EPF. In this study, recovered microfossils were largely $>500 \mu \mathrm{m}$, suggesting this technique may be more appropriate for liberating larger microfossils (e.g. LFs); however, we discuss nuances to the method that would allow for more effective recovery of smaller microfossil specimens. The more traditional acetic acid method was also able to disaggregate a number of the samples; however, preservation of the LF was compromised. We suggest a best-practice methodology for implementing EPF in micropalaeontological studies.
\end{abstract}

\section{Introduction}

Indurated carbonate-rich sedimentary rocks (e.g. limestones) are notoriously difficult to disaggregate, something that is essential when liberated microfossils are required for taxonomic or geochemical analyses. "Traditional" methods (i.e. those well documented within current literature) used for disaggregation of deep-sea sediments, such as Calgon, cannot break apart the well-cemented matrix, and methods utilising stronger acids risk damaging microfossils that are themselves often composed of calcium carbonate. Alternative techniques are therefore required to successfully liberate microfossils in such indurated carbonates. The biostratigraphic study of larger foraminifera (LF) in these rocks is more commonly achieved through the use of thin sections or acetate peels; however, the resultant "cut" through the rock may not allow for successful identification to a specific or generic level. In order to identify LF to species level, the specimen must be orientated either on its axial or equatorial axis (Fig. 1). As such, liberated specimens from which individual thin sections can be made are preferred. Similarly, it is extremely difficult to identify smaller foraminifera accurately from thin sections, as various aspects of their external morphology (e.g. the surface of their tests) need to be assessed for specific level identification.

The difficulty in liberating microfossils from indurated carbonates is a widespread problem which is especially ubiquitous when studying outcrop samples which have of- 


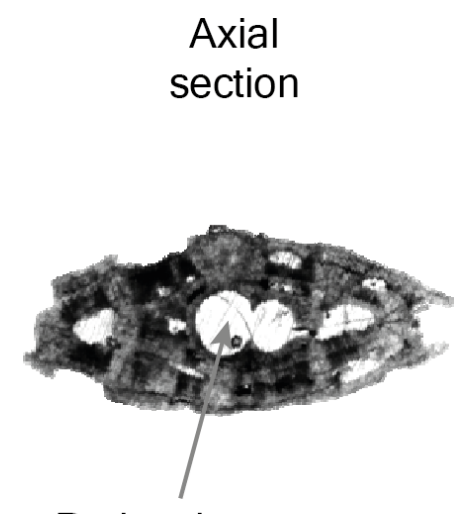

Proloculus

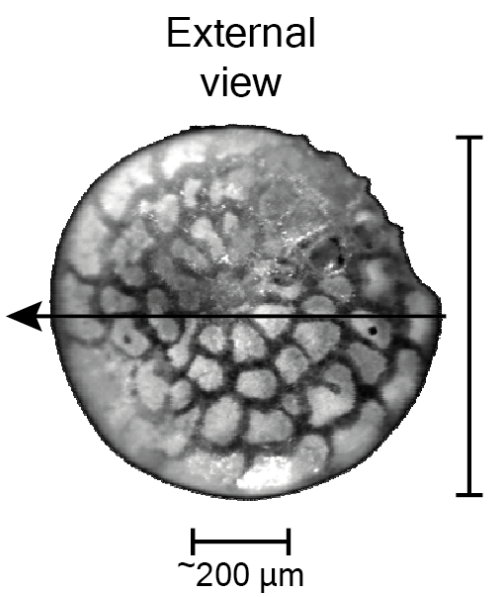

External

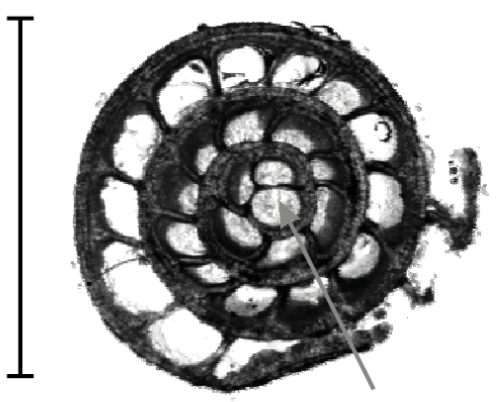

Proloculus

Figure 1. The equatorial and axial orientation of larger foraminifera thin section samples (foraminifera images from Cotton, 2012).

ten been subjected to weathering and enhanced cementation. However, there is a wealth of information to be gained from detailed study of ancient shallow water carbonate settings, which are often exposed as outcrops rather than cores. As such, we have investigated whether electric pulse fragmentation (EPF) is a possible improvement over traditional rock disaggregation techniques to aid microfossil recovery in these lithologies. Commonly used for liberation of coarse zircon grains for geochronological studies, EPF as a tool for microfossil liberation was proposed by Saini-Eidukat and Weiblen (1996); their study successfully liberated a range of microfossil (conodonts, foraminifera, juvenile ammonites, ostracods) and macrofossil (belemnite tip, fossil moulds, fish teeth) material from shales and sandstones. Liberated material was composed of moulds. Despite further industrialisation and more commercially available EPF systems, this technique has not yet been investigated further. More specifically, this method has not previously been applied to any carbonate sediments, within which microfossil and macrofossil material can be abundant.

In an initial pilot study, we successfully liberated LF from surrounding carbonate cement in one sample from the United Arab Emirates (UAE) shallow-water Umm Err Radhuma formation: an indurated, bioclastic Paleogene carbonate (Parvaz et al., 2018). To further test the effectiveness of EPF in LF liberation, we compare it against two traditional methods: Calgon and acetic acid. These two methods were chosen as they represent use of an acid (acetic acid) and a surfactant (Calgon) to disaggregate samples; these are categories into which most other disaggregation techniques fall into (Hodgkinson, 1991). We therefore feel these are representative for comparison across a wide range of techniques. We assess the effectiveness and efficiency of each of these methods in liberating LF from carbonate-rich lithologies by comparing disaggregation time, percentage fossiliferous fraction and number of liberated specimens.

\section{Materials and methods}

A total of nine field samples from strata of Paleogene age were investigated; each was subjected to disaggregation using three different techniques. Samples were collected on field campaigns in Tanzania, Malta and the UAE; they consisted dominantly of carbonate-rich, bioclastic grainstones with extensive diagenetic cements of varying composition (Table 1). All samples were deposited in a dominantly shallow-water environment $(<250 \mathrm{~m})$ with a diverse assemblage of shallow-water biota present (LF, ostracods, bryozoans, red and green algae). Samples have undergone various stages of diagenesis and are therefore highly lithified with diagenetic cements. The details of the field samples are shown in Table 1. Hand specimen and thin section images are shown in Figs. 2 and 3, respectively.

Two traditional methods (Calgon and acetic acid) used in disaggregating carbonates were employed in order to compare against the new technique (EPF). Each of the nine bulk samples were first imaged (Fig. 2), and one thin section of each sample was made (Fig. 3). Then, three equal-sized amounts of the rocks were broken off from each sample. The resultant amount was dependent upon the initial size of the sample, but each was at least $20 \mathrm{~g}$.

Once the samples were disaggregated using each of the three methods below a selection of liberated microfossil material from each method was imaged using a scanning electron microscope.

\subsection{Method 1: Calgon (modification of Riding and Kyffin-Hughes, 2004)}

Immersion in cold Calgon is a technique often used to disaggregate less well-indurated calcium carbonate samples (e.g. deep sea oozes, chalks) for the study of smaller microfossils (e.g. Barnet et al., 2019; their Supplement). Within these lithologies this technique can be extremely effective 

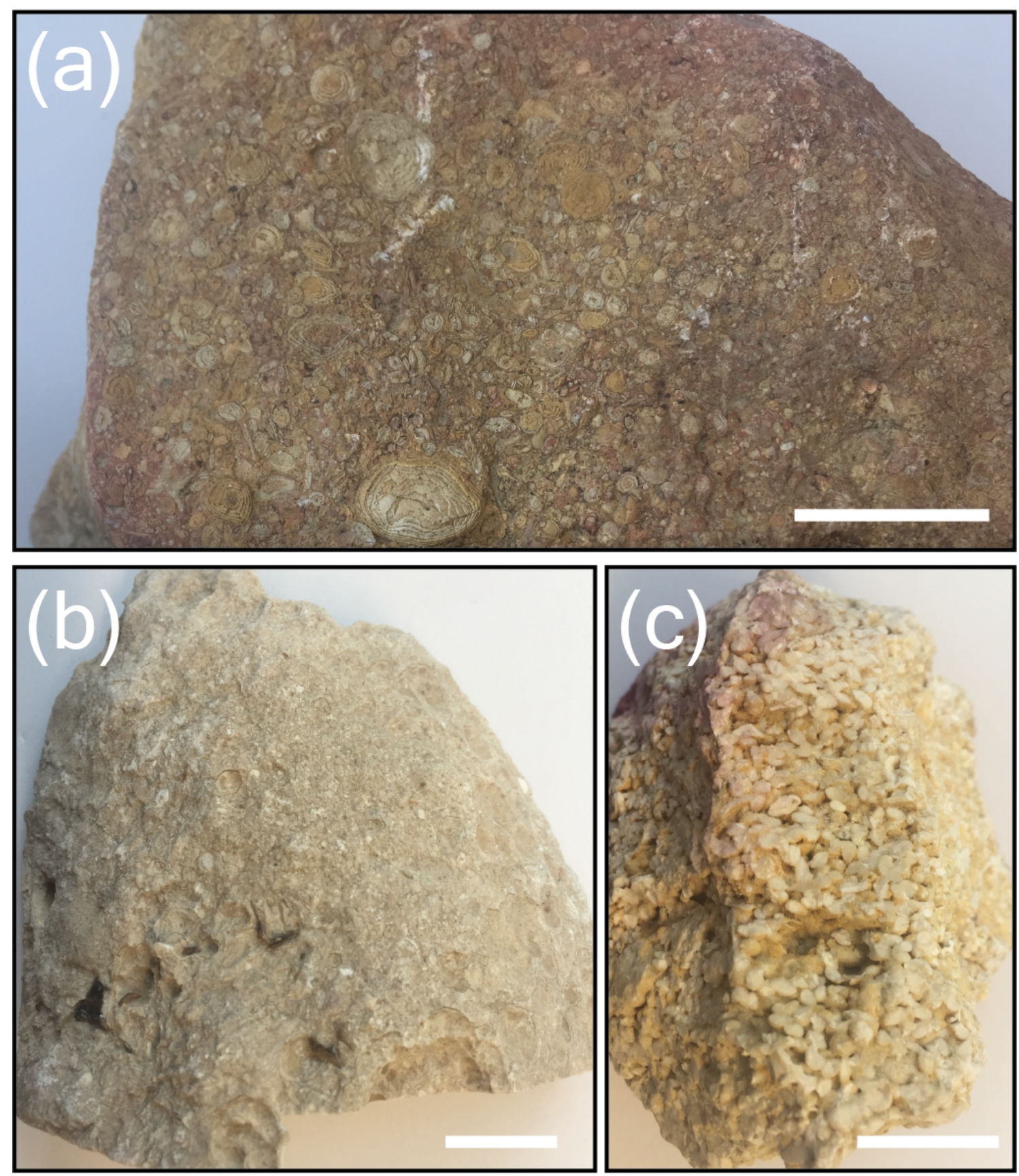

Figure 2. Hand specimen images of three samples. These show the range of fossiliferous carbonate sediments that were tested with the three disaggregation methods: (a) LF packstone-grainstone (sample K16), (b) bioclastic wackestone (sample JB1) and (c) LF packstone (sample L05). Scale bars are $2 \mathrm{~cm}$.

at disaggregating the microfossiliferous content from the carbonate-clay matrix. Although extensively used, this modified technique for use on calcareous foraminifera has rarely been described in full (Riding and Kyffin-Hughes, 2004); as such it is described in full below. The technique requires a buffered (pH-controlled) solution of sodium hexametaphosphate $\left(\left[\mathrm{NaPO}_{3}\right]_{6}\right)$ to limit the damage that a stronger acid can have on dissolution susceptible calcium carbonate tests
(Hodgkinson, 1991). This is achieved by adding sodium carbonate $\left(\mathrm{Na}_{2} \mathrm{CO}_{3}\right)$ to the solution in the following proportion: $10 \mathrm{~L}$ deionised $\mathrm{H}_{2} \mathrm{O}, 20 \mathrm{~g}\left(\mathrm{NaPO}_{3}\right)_{6}$ and $1.4 \mathrm{~g} \mathrm{Na}_{2} \mathrm{CO}_{3}$. The cold Calgon solution method works due to the deflocculating nature of the phosphate ions present. They reduce the coherence of clay particles by adsorbing strongly to the particle surface, breaking apart the clays due to the high ionic charges (Riding and Kyffin-Hughes, 2004). 

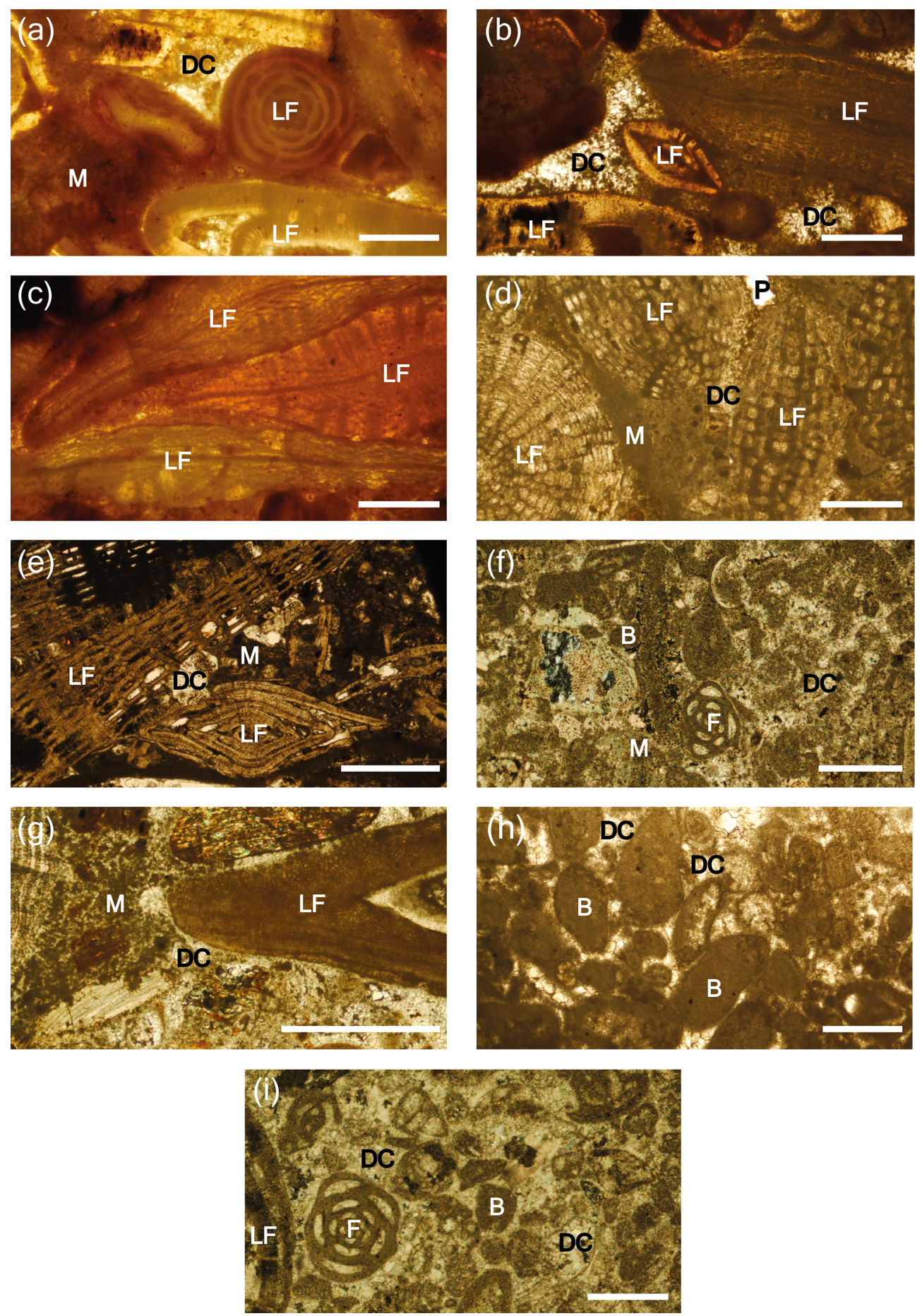

Figure 3. Example thin section images of the bulk samples showing the range of biota and amount and type of cement. Images taken with transmitted light microscope; XPL stands for crossed polarised light, and PPL stands for plane polarised light. White scale bars are $500 \mu \mathrm{m}$ in each image. (a) LF packstone (?Alveolina and nummulitids) with quartz grains within a clay matrix (sample K05 in XPL). (b) LF packstone (nummulitid and orthophragmine) with quartz grains within a clay matrix (sample K09 in PPL). (c) LF packstone-grainstone (orthophragmine) with quartz grains within a clay matrix (sample K16 in PPL). (d) LF packstone (miogypsinids and Sphaerogypsina) with thin calcitic meniscus cement (sample L05 in PPL). (e) LF packstone (Lepidocyclina and nummulitid) with calcite cement, clay matrix and quartz grains (sample LCL in PPL). (f) Bioclastic wackestone with secondary calcite cement (sample JB1 in XPL). (g) Bioclastic wackestone with secondary calcite cement (sample JB3 in XPL). (h) Bioclastic grainstone with secondary calcite cement (sample JF2 in PPL). (i) Foraminifera wackestone with secondary calcite cement (sample JH1 in XPL). LF stands for larger foraminifera, DC stands for diagenetic cement, $\mathrm{M}$ stands for matrix sediment, $\mathrm{P}$ stands for porosity, F stands for foraminifera and B stands for other bioclast. Further sample descriptions can be found in Table 1. 
Table 1. Details of the different samples used in this study. The details of the biota were identified in thin sections and are shown in Fig. 2.

\begin{tabular}{|c|c|c|c|c|c|}
\hline $\begin{array}{l}\text { Sample } \\
\text { name }\end{array}$ & $\begin{array}{l}\text { Locality } \\
\text { (latitude, } \\
\text { longitude) }\end{array}$ & Bioclasts & Type of cement or matrix & $\begin{array}{l}\text { Facies type; } \\
\text { approximate age }\end{array}$ & $\begin{array}{l}\text { References and formation } \\
\text { names }\end{array}$ \\
\hline K05 & $\begin{array}{l}\text { Kilwa, Tanzania } \\
\left(08^{\circ} 55^{\prime} \mathrm{S}\right. \\
\left.039^{\circ} 30^{\prime} \mathrm{E}\right)\end{array}$ & $\begin{array}{l}\text { LF (Discocyclina spp., } \\
\text { Nummulites spp., } \\
\text { Assilina spp.), complex } \\
\text { miliolids, green algae. }\end{array}$ & $\begin{array}{l}\text { Coarse-grained quartz } \\
\text { grains within clay matrix } \\
\text { infilling porosity. }\end{array}$ & $\begin{array}{l}\text { LF packstone; } \\
\text { Eocene }\end{array}$ & $\begin{array}{l}\text { Kilwa group, Masoko For- } \\
\text { mation (e.g. Nicholas et al., } \\
\text { 2006) }\end{array}$ \\
\hline K09 & $\begin{array}{l}\text { Kilwa, Tanzania } \\
\left(08^{\circ} 55^{\prime} \mathrm{S}\right. \\
\left.039^{\circ} 30^{\prime} \mathrm{E}\right)\end{array}$ & $\begin{array}{l}\text { LF (Nummulites spp., } \\
\text { Discocyclina spp., other } \\
\text { orthophragmines). }\end{array}$ & $\begin{array}{l}\text { Fine-grained quartz grains } \\
\text { within clay matrix infilling } \\
\text { porosity. }\end{array}$ & $\begin{array}{l}\text { LF packstone; } \\
\text { Eocene }\end{array}$ & $\begin{array}{l}\text { Kilwa group, Masoko For- } \\
\text { mation (e.g. Nicholas et al., } \\
\text { 2006) }\end{array}$ \\
\hline K16 & $\begin{array}{l}\text { Kilwa, Tanzania } \\
\left(09^{\circ} 16^{\prime} \mathrm{S}\right. \\
\left.039^{\circ} 31^{\prime} \mathrm{E}\right)\end{array}$ & $\begin{array}{l}\text { LF (Nummulites spp., } \\
\text { Assilina spp., } \\
\text { Discocyclina spp., other } \\
\text { orthophragmines). }\end{array}$ & $\begin{array}{l}\text { Fine-grained quartz grains } \\
\text { and sporadic clay matrix in- } \\
\text { filling porosity. }\end{array}$ & $\begin{array}{l}\text { LF packstone- } \\
\text { grainstone; } \\
\text { Eocene }\end{array}$ & $\begin{array}{l}\text { Kilwa group, Masoko For- } \\
\text { mation (e.g. Nicholas et al., } \\
\text { 2006) }\end{array}$ \\
\hline L05 & $\begin{array}{l}\text { Near Mbanja, } \\
\text { Tanzania } \\
\left(09^{\circ} 52^{\prime} \mathrm{S}\right. \\
\left.039^{\circ} 44^{\prime} \mathrm{E}\right)\end{array}$ & $\begin{array}{l}\text { LF (miogypsinids, } \\
\text { lepidocyclinids, Sphaer- } \\
\text { ogypsina spp.), red algae. }\end{array}$ & $\begin{array}{l}\text { Thin calcitic meniscus } \\
\text { cement between bioclasts. } \\
\text { Clay lining pores. }\end{array}$ & $\begin{array}{l}\text { LF packstone; } \\
\text { Miocene }\end{array}$ & $\begin{array}{l}\text { Miocene; not formally } \\
\text { described in literature } \\
\text { (Nicholas et al., 2006) }\end{array}$ \\
\hline LCL & $\begin{array}{l}\text { Il Mara, Malta } \\
\left(35^{\circ} 48^{\prime} \mathrm{N}\right. \\
\left.14^{\circ} 31^{\prime} \mathrm{E}\right)\end{array}$ & $\begin{array}{l}\text { LF (lepidocyclinids, } \\
\text { nummulitids). }\end{array}$ & $\begin{array}{l}\text { Fine-grained secondary cal- } \\
\text { cite cement. Quartz grains } \\
\text { within clay matrix. }\end{array}$ & $\begin{array}{l}\text { LF packstone; } \\
\text { Oligocene }\end{array}$ & $\begin{array}{l}\text { Lower Coralline limestone } \\
\text { Formation (e.g. Pedley, } \\
\text { 1975) }\end{array}$ \\
\hline JB1 & $\begin{array}{l}\text { Jebel Buhays, } \\
\text { UAE } \\
\left(25^{\circ} 01^{\prime} \mathrm{N}\right. \\
\left.55^{\circ} 47^{\prime} \mathrm{E}\right)\end{array}$ & $\begin{array}{l}\text { Smaller benthic } \\
\text { foraminifera, complex } \\
\text { miliolids. }\end{array}$ & $\begin{array}{l}\text { Coarse-grained secondary } \\
\text { calcite cement. }\end{array}$ & $\begin{array}{l}\text { Bioclastic } \\
\text { wackestone; } \\
\text { Paleocene/Eocene }\end{array}$ & $\begin{array}{l}\text { Muthaymimah/Rus Forma- } \\
\text { tion (e.g. Abdelghany and } \\
\text { Abu Saima, 2013) }\end{array}$ \\
\hline JB3 & $\begin{array}{l}\text { Jebel Buhays, } \\
\text { UAE } \\
\left(25^{\circ} 01^{\prime} \mathrm{N}\right. \\
\left.55^{\circ} 47^{\prime} \mathrm{E}\right)\end{array}$ & $\begin{array}{l}\text { LF (nummulitids, } \\
\text { orthophragmines), } \\
\text { red algae. }\end{array}$ & $\begin{array}{l}\text { Primary isopachous crust, } \\
\text { secondary fine-grained cal- } \\
\text { cite cement. }\end{array}$ & $\begin{array}{l}\text { Bioclastic } \\
\text { wackestone; } \\
\text { Paleocene/Eocene }\end{array}$ & $\begin{array}{l}\text { Muthaymimah/Rus Forma- } \\
\text { tion (e.g. Abdelghany and } \\
\text { Abu Saima, 2013) }\end{array}$ \\
\hline JF2 & $\begin{array}{l}\text { Jebel Faiyah, } \\
\text { UAE } \\
\left(25^{\circ} 05^{\prime} \mathrm{N}\right. \\
\left.55^{\circ} 49^{\prime} \mathrm{E}\right)\end{array}$ & $\begin{array}{l}\text { Smaller benthic } \\
\text { foraminifera, algae. }\end{array}$ & $\begin{array}{l}\text { Coarse-grained secondary } \\
\text { calcite cement. }\end{array}$ & $\begin{array}{l}\text { Bioclastic grain- } \\
\text { stone; } \\
\text { Paleocene/Eocene }\end{array}$ & $\begin{array}{l}\text { Muthaymimah Formation } \\
\text { (e.g. Nolan et al., 1990) }\end{array}$ \\
\hline JH1 & $\begin{array}{l}\text { Jebel Hafeet, } \\
\text { UAE } \\
\left(24^{\circ} 03^{\prime} \mathrm{N}\right. \\
\left.55^{\circ} 45^{\prime} \mathrm{E}\right)\end{array}$ & $\begin{array}{l}\text { LF (Nummulites spp., } \\
\text { alveolinids), complex } \\
\text { miliolids, smaller benthic } \\
\text { foraminifera. }\end{array}$ & $\begin{array}{l}\text { Fine-grained secondary cal- } \\
\text { cite cement. }\end{array}$ & $\begin{array}{l}\text { Foraminifera } \\
\text { wackestone; } \\
\text { early Eocene }\end{array}$ & $\begin{array}{l}\text { Dammam Formation (e.g. } \\
\text { Abdelghany, 2002) }\end{array}$ \\
\hline
\end{tabular}

The precise method used in this study is as follows: the samples were first broken up with a hammer into small (maximum $2 \mathrm{~cm}$ ) chunks. Due to the heavily indurated nature of samples JB1, JF2 and JH1 it was not possible to break them down to this smaller size without fracturing the fossiliferous content. These chunks were then placed into a beaker and covered with cold Calgon (buffered sodium hexametaphosphate, i.e., $\left(\mathrm{NaPO}_{3}\right)_{6}$; as described above) and left for $24 \mathrm{~h}$. Samples were then washed over a $63 \mu \mathrm{m}$ sieve with deionised water, put back into the beaker, covered again with Calgon and left for $48 \mathrm{~h}$. The beakers were then placed on a shaker table for $2 \mathrm{~h}$, washed again over a $63 \mu \mathrm{m}$ sieve and subsequently covered again in Calgon. After $24 \mathrm{~h}$, the samples were placed on a shaker table for $2 \mathrm{~h}$, washed over a $63 \mu \mathrm{m}$ sieve and dried in an oven overnight at $50^{\circ} \mathrm{C}$.

\subsection{Method 2: acetic acid (after Lirer, 2000)}

The cold acetic acid method proposed by Lirer (2000) has been widely used to extract microfossiliferous material from indurated rocks (e.g. Jovane et al., 2007; Falzoni et al., 2016; D'Onofrio and Luciani, 2020). The free hydrogen ions in the acid work to attack the matrix of the rock, dissolving it and breaking it apart (Hodgkinson, 1991; Costa de Moura et al., 1999). Costa de Moura et al. (1999) suggest the impurities present in the matrix of carbonate rocks provide boundaries 
for the acid to work on more effectively, whereas the pure biogenic carbonate of a fossil test can be considered more impermeable to the acid. However, assemblage diversity losses have been reported in planktic foraminifera after sample processing with acetic acid, showing that the acid can also attack the calcium carbonate of foraminifera tests (D'Onofrio and Luciani, 2020).

As with method 1, samples were broken into small (maximum $2 \mathrm{~cm}$ ) chunks, except in samples JB1, JF2 and JH1 where it was not possible to break them down to this smaller size without fracturing the fossiliferous content. Samples were placed into $250 \mathrm{~mL}$ beakers, covered with an $80 \%$ acetic acid and $20 \%$ deionised water solution, and left in a fume cupboard for $24 \mathrm{~h}$. After this time, samples were washed with deionised water over a $63 \mu \mathrm{m}$ sieve and the residue dried overnight in an oven at $50^{\circ} \mathrm{C}$. Due to there being very little organic material in the samples it was not necessary to use the "Desogen" (or neosteramina; D' Onofrio and Luciani, 2020) step in the Lirer (2000) method.

\subsection{Method 3: electric pulse fragmentation (EPF; Saini-Eidukat and Weiblen, 1996; Parvaz et al., 2018)}

The electric pulse fragmentation (EPF) method utilises highly energetic (150-750 J per pulse), pulsed electrical discharges with a very fast voltage ramp-up time $(<500 \mathrm{~ns})$ to break apart composite materials submerged in a process medium along internal compositional or mechanical boundaries. Dielectric process mediums such as water are more resistive than solids when the pulse rise time is kept below $500 \mathrm{~ns}$, resulting in discharges preferentially grounding on the solid material (Bluhm et al., 2000). In each discharge a movement of electrons, as plasma, occurs from the working electrode to the ground electrode (Andres et al., 1999; van der Wielen, 2013). This plasma channel causes explosive expansion along the discharge pathway (electrodynamic fragmentation; Andres et al., 1999; Bluhm et al., 2000), producing a shockwave that propagates through the material.

The selectivity of the process arises from the interaction of the plasma channel and shockwaves with physico-chemical properties of the material. Discontinuities in electrical permittivity and conductivity at phase boundaries locally enhance the electric field, forcing the discharge channels to these boundaries. The interaction of the shock wave with elastic and acoustic discontinuities concentrates tensile stress at phase interfaces, causing local shearing and thus focussing fragmentation at these boundaries (Andres et al., 1999) and allowing full liberation of discrete components from the feed material. Applicable to a range of disciplines, EPF treatment of various mineral ores has previously shown very high liberation rates (Andres et al., 1999, 2001; Dal Martello et al., 2012; Wang et al., 2012; Bru et al., 2017, 2020), advocating for its potential use in micropalaeontology.
Table 2. Variable parameters of the SELFRAG Lab system.

\begin{tabular}{lr}
\hline Parameter & Range \\
\hline Electrode gap & $10-40 \mathrm{~mm}$ \\
Pulse retention rate & $1-5 \mathrm{~Hz}$ \\
Voltage & $90-200 \mathrm{kV}$ \\
Number of pulses & $1-1000$ \\
Sieve aperture & $0.12-10 \mathrm{~mm}$ \\
\hline
\end{tabular}

For this study, EPF treatment was performed using a SELFRAG "Lab" (Fig. 4), a laboratory-scale device for the batch processing of material that is manufactured by SELFRAG AG of Switzerland. The equipment is designed to process samples of up to approximately $1 \mathrm{~kg}$ with a top particle size of $40-45 \mathrm{~mm}$ in a $4 \mathrm{~L}$ vessel filled with demineralised water process medium. The working electrode is immersed in the upper part of the vessel, while the bottom of the vessel constitutes the counter electrode (ground). The apparatus produces high-voltage electric discharges between the two electrodes. Operating parameters are presented in Table 2. The lab system can be operated with both a "closed" vessel for when a fixed amount of energy is to be applied to a fixed mass of material and an "open" vessel where the solid lower plate is replaced with a sieve that allows material reaching the target size during crushing to fall through and be protected from further discharge events.

Samples were manually crushed to $40-45 \mathrm{~mm}$ to fit into the process vessel. Measurement of the LF to be recovered guided selection of an appropriate aperture sieve for the SELFRAG open-process vessel. Normally the aperture diameter is $\sim 1.5 \times$ the target particle diameter. Due to the unknown breakage behaviour of these samples, a larger diameter aperture was used in the first round of crushing and a stepwise crushing process was implemented. A series of 10 pulses were applied to the sample, followed by visual inspection of the remaining sample; if $>10 \%$ of the sample remained above the sieve another 5-10 pulses were administered. When $>90 \%$ of sample material had passed through the sieve, treatment was stopped, and the sample was recovered from the process vessel collection cup (SELFRAG AG, 2012) before drying at $50^{\circ} \mathrm{C}$. Process conditions and total pulses applied to each sample are found in Table 3.

After samples were dried, liberated LF were manually picked from the sample and the remaining material, comprising both particles of LF with attached matrix and only matrix, was returned to the process vessel and reprocessed (Table 3). A lower voltage of $160 \mathrm{kV}$ was used in the second round to minimise the electrical crushing energy per pulse. Accordingly, the electrode gap was reduced to maintain the concentration of the electrical field and increase probability of successful discharges (van der Wielen, 2013). 

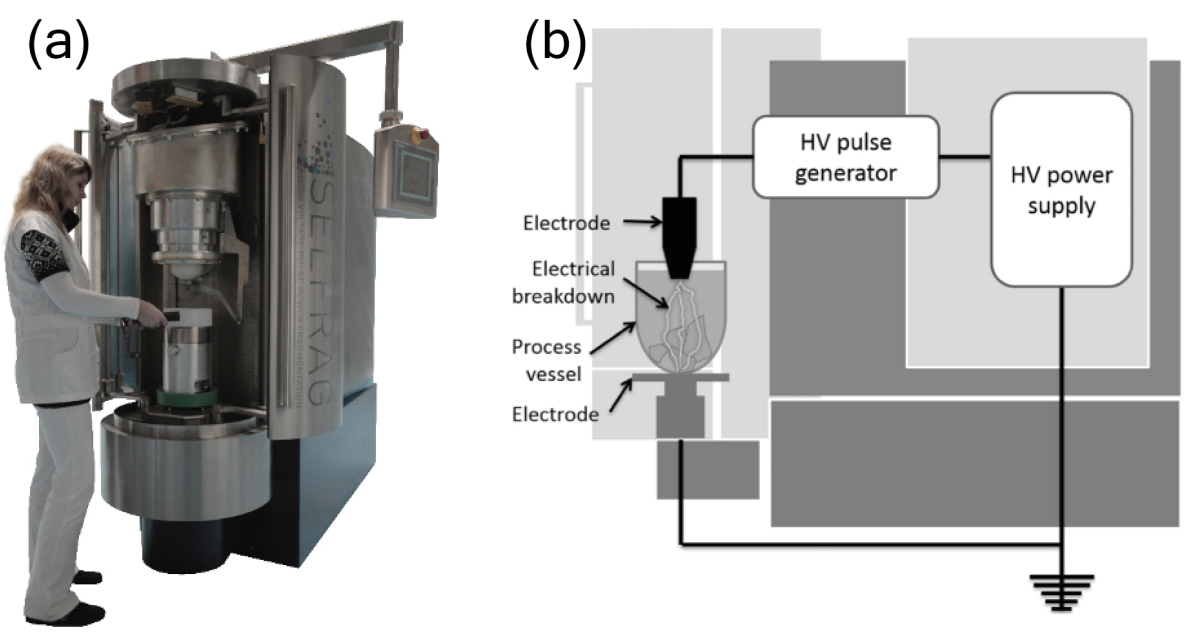

Figure 4. Photograph (a) and schematic (b) of the SELFRAG Lab system (after Bru et al., 2018).

Table 3. First- and second-round process conditions for EPF-treated samples. Sieve aperture was selected based on measurement of visible LF. The electrode gap is smaller for K05 due to much smaller sample mass. Sample JH1 was not reprocessed as all material was processed successfully in the first processing round.

\begin{tabular}{|c|c|c|c|c|c|c|c|}
\hline $\begin{array}{l}\text { Sample } \\
\text { ID }\end{array}$ & $\begin{array}{r}\text { Processing } \\
\text { round }\end{array}$ & $\begin{array}{r}\text { Sieve } \\
\text { aperture } \\
(\mathrm{mm})\end{array}$ & $\begin{array}{r}\text { Electrode } \\
\text { gap } \\
(\mathrm{mm})\end{array}$ & $\begin{array}{r}\text { Pulse } \\
\text { repetition } \\
\text { rate }(\mathrm{Hz})\end{array}$ & $\begin{array}{r}\text { Voltage } \\
(\mathrm{kV})\end{array}$ & $\begin{array}{l}\text { Total } \\
\text { pulse } \\
\text { count }\end{array}$ & $\begin{array}{r}\text { Processing } \\
\text { time (s) }\end{array}$ \\
\hline \multirow[t]{2}{*}{ K05 } & 1 & 6 & 20 & 2 & 150 & 20 & 10 \\
\hline & 2 & 4 & 20 & 2 & 160 & 40 & 20 \\
\hline \multirow[t]{2}{*}{ K09 } & 1 & 6 & 40 & 2 & 175 & 20 & 10 \\
\hline & 2 & 4 & 20 & 2 & 160 & 40 & 20 \\
\hline \multirow[t]{2}{*}{ K16 } & 1 & 6 & 40 & 2 & 175 & 20 & 10 \\
\hline & 2 & 4 & 20 & 2 & 160 & 40 & 20 \\
\hline \multirow[t]{2}{*}{ L05 } & 1 & 6 & 40 & 2 & 175 & 10 & 5 \\
\hline & 2 & 4 & 20 & 2 & 160 & 20 & 10 \\
\hline \multirow[t]{2}{*}{ LCL } & 1 & 6 & 40 & 2 & 175 & 20 & 10 \\
\hline & 2 & 4 & 20 & 2 & 160 & 40 & 20 \\
\hline \multirow[t]{2}{*}{ JB1 } & 1 & 6 & 40 & 2 & 175 & 40 & 20 \\
\hline & 2 & 4 & 20 & 2 & 160 & 40 & 20 \\
\hline \multirow[t]{2}{*}{ JB3 } & 1 & 6 & 40 & 2 & 175 & 20 & 10 \\
\hline & 2 & 4 & 20 & 2 & 160 & 40 & 20 \\
\hline \multirow[t]{2}{*}{$\mathrm{JF} 2$} & 1 & 6 & 40 & 2 & 175 & 30 & 15 \\
\hline & 2 & 4 & 20 & 2 & 160 & 60 & 30 \\
\hline \multirow[t]{2}{*}{ JH1 } & 1 & 10 & 40 & 2 & 175 & 30 & 15 \\
\hline & $\mathrm{n} / \mathrm{a}$ & - & - & - & - & - & - \\
\hline
\end{tabular}

n/a - not applicable. 


\subsection{Normalising number of liberated microfossils}

\subsubsection{Larger foraminifera per gram}

Number of larger foraminifera picked in each sample was normalised per gram of original sample, due to varying size of the original sample. The entirety of each sample was picked. For the purposes of comparison, we consider a "good disaggregation" to be where more than two larger foraminifera per gram of sediment were liberated.

\subsubsection{Percentage fossiliferous fraction (\% FF)}

Percentage fossiliferous fraction data $(\% \mathrm{FF})$ were obtained by first weighing the bulk disaggregated sediment $\left(\right.$ bulk $\left._{\mathrm{w}}\right)$, composed of chunks of non-disaggregated carbonate sediment and liberated fossils. The bulk sediment was dried in an oven at $50^{\circ} \mathrm{C}$ after each of the disaggregation methods were applied to ensure measured weights were accurate. The $>63 \mu \mathrm{m}$ fossiliferous fraction was then weighed once picked $\left(\mathrm{FF}_{\mathrm{W}}\right)$. The entirety of each disaggregated sample was picked for all fossiliferous material. This mainly consisted of LF; however, a number of ostracods were also picked. In order to normalise the data to the original bulk weight of the material, the $\% \mathrm{FF}$ was calculated using the following equation.

$\% \mathrm{FF}=\left(\mathrm{FF}_{\mathrm{w}} / \mathrm{bulk}_{\mathrm{w}}\right) \times 100$

By normalising the data in this way, it removes the issues of each sample being of a different starting mass. As such, good disaggregation of samples is shown by a larger \% FF.

\subsection{Scanning electron microscope (SEM) and energy dispersive spectroscopy (EDS)}

Scanning electron microscope and energy dispersive spectroscopy (SEM-EDS) work was carried out at the University of Exeter, Penryn Campus, on a TESCAN VEGA3 GMU SEM with an Oxford XMax $80 \mathrm{~mm}$ EDS linked to AZtec analysis software. Samples were carbon coated prior to analysis and examined at $20 \mathrm{kV}$ at a working distance of $\sim 11 \mathrm{~mm}$ for imaging and $\sim 17 \mathrm{~mm}$ for EDS analysis. The EDS data were assessed in semi-quantitative mode with an acquisition time of $10 \mathrm{~s}$. Data were used to confirm the mineralogy of diagenetic cements and matrix materials in samples (Table 1).

\section{Results}

\subsection{Calgon}

Despite leaving all samples in Calgon for approximately $112 \mathrm{~h}$ in total, this method was not effective at disaggregating any of the samples. This is illustrated in Figs. 5 and 6, where extremely few $\left(<2 \mathrm{~g}^{-1}\right)$ or no LF were liberated, and the percentage fossiliferous fraction was low throughout all processed samples. Where LF were liberated, the residual matrix and cement remained attached to the outside of the test
(Fig. 7e and f). It seems unlikely that leaving the samples to sit in the Calgon for a more extended period of time would have led to a significantly improved disaggregation.

\subsection{Acetic acid}

Three samples, a LF packstones (sample K05 and LCL) and a foraminifera wackestone (sample JH1), disaggregated well with the acetic acid method in terms of numbers of foraminifera liberated per gram (Fig. 5). The highest fossiliferous fraction, of $19.65 \%$, was recorded using this method with sample K05 (Fig. 6); this sample is an LF packstone of Eocene age with a clay matrix containing quartz grains. All other samples had poor recoveries of LF using the acetic acid method ( $<2$ LF per gram and low \% FF). In all cases, liberated LF were not well preserved following the acetic acid method, with test surfaces having been etched by the strong acid (Fig. 7), likely due to any disaggregation requiring at least $24 \mathrm{~h}$ of immersion.

\subsection{Electric pulse fragmentation}

Four samples disaggregated well with the EPF method both in terms of overall numbers of LF liberated per gram (Fig. 5) and percentage fossiliferous fraction (Fig. 6); these were LF packstones with clay matrices containing quartz grains (samples K05 and K09), a LF packstone with thin calcitic meniscus cement (sample L05), and a LF packstone with a calcite and clay matrix and small patches of quartz grains (sample LCL). All of these samples had bioclasts of $500 \mu \mathrm{m}$ or larger (Table 1). Within these samples, an average of $182 \%$ more LF per gram were liberated using EPF when compared to Calgon, and $57 \%$ more when compared to acetic acid.

Only two samples yielded more liberated LF per gram when using the acetic acid method (Fig. 5): K05, a LF packstone, yielded $35 \%$ more LF, and JH1, a foraminifera wackestone, yielded $72 \%$ more LF. For all samples, preservation of liberated LF using the EPF technique was good; there was minimal fragmentation, no dissolution of the test surface, and little or no matrix or cement that remained attached to the test surfaces (Fig. 7). EPF liberation gave some of the highest overall recoveries of LF.

\subsection{Poor disaggregation}

Four samples did not disaggregate well with any of the three methods (Figs. 5 and 6); samples remained in large lithified chunks with little or no microfossil material liberated. These were bioclastic wackestones (samples JB1, JB3) and grainstones (sample JF2) with secondary calcite cements and a LF packstone-grainstone with abundant bioclasts and a clay matrix containing quartz grains (sample K16). 


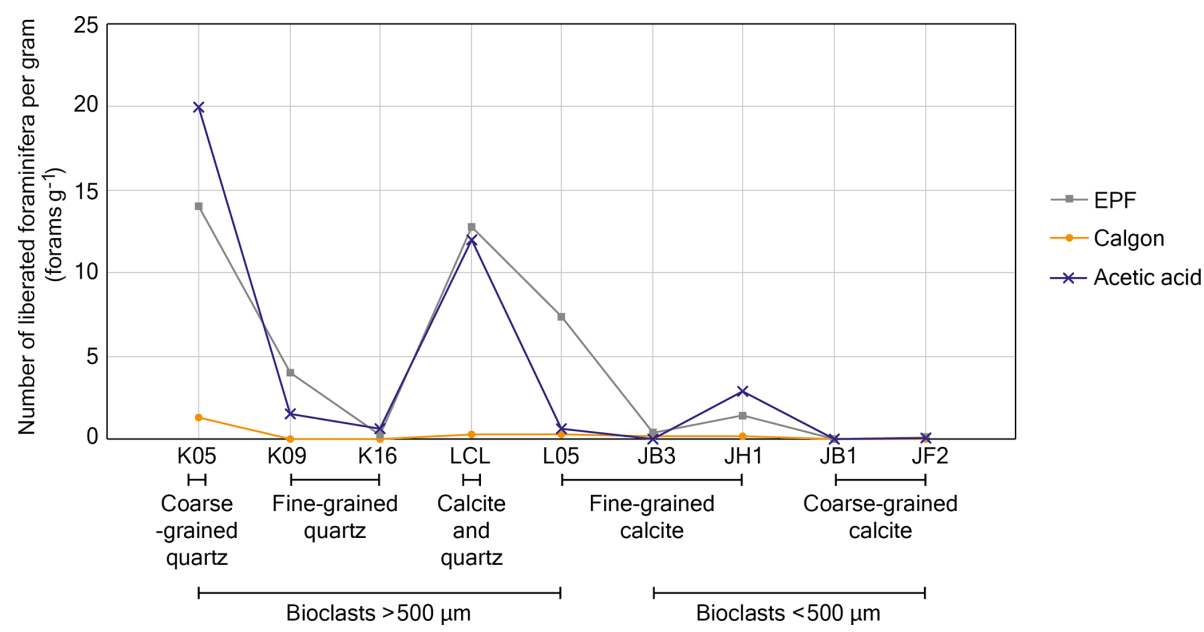

Figure 5. Number of liberated larger foraminifera per gram of each sample for each of the three methods. Samples are organised into types of infilling cements and sizes of bioclasts; further details can be found in Tables 1 and 4 .

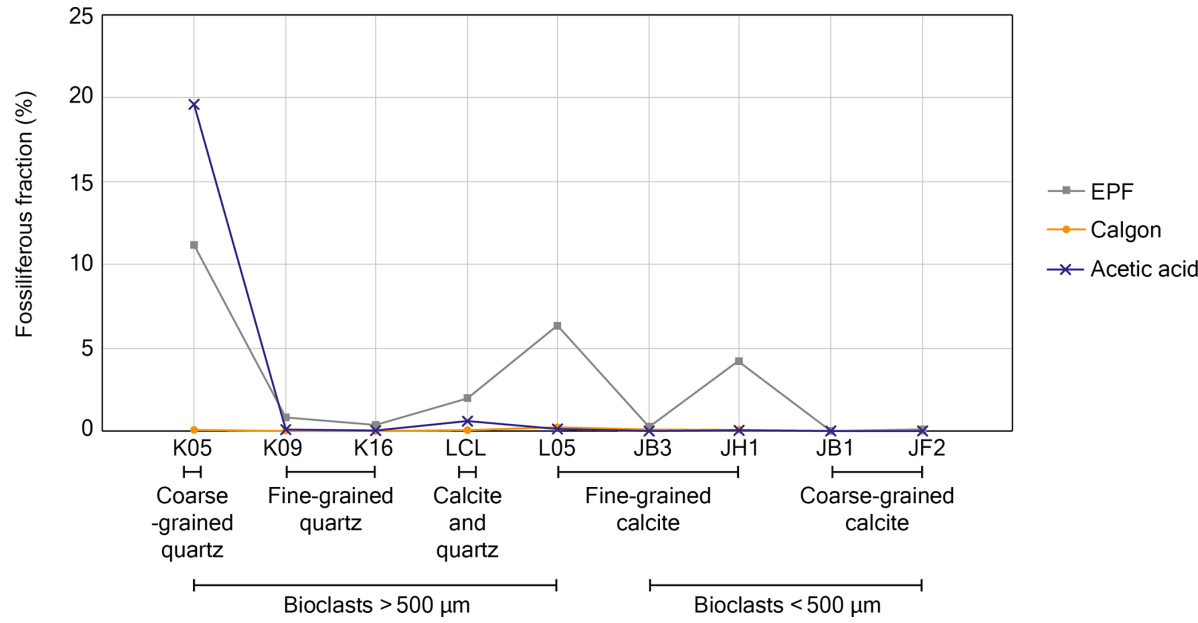

Figure 6. Percentage fossiliferous fraction $(>63 \mu \mathrm{m})$ for each sample from the three different methods. Samples are organised into types of infilling cements and sizes of bioclasts; further details can be found in Tables 1 and 4.

\section{Discussion}

The development of this new methodology, and comparison to other disaggregation techniques, aims to enable higher resolution study of the ancient low-latitude shallow water domain, which is often dominated by indurated calcium carbonate-rich sediments. Whilst there are numerous existing high-resolution palaeoclimate and micropalaeontological records from deep-water settings of Paleogene age, similar resolution records in shallow-water environments are comparatively rare, impeding comparisons of shallow and deep lithologies and the understanding of how these important palaeoenvironments and ecosystems, such as reefs, have evolved. The ability to break apart lithified carbonates into their constituent components enables the study of a wide variety of microfossil material, such as LF, algae (e.g. Rhodoliths), bryozoans, fish teeth, conodonts and more. Ex- pansion of existing studies of evolutionary trends in individual taxa, ecophenotypic variation, species-level biodiversity trends, carbonate platform dynamics and much more thus becomes possible. Whilst other non-destructive techniques such as CT scanning are also possible (e.g. Renema and Cotton, 2015) this cannot be routinely undertaken as bioclasts need to be unfilled (e.g. the chambers must be free of cement) for optimal results and the technique is expensive and time-consuming; therefore, this technique is not suitable for many samples.

There are also other techniques available utilising different strong acids and surfactants in order to break apart fossiliferous lithologies. One such example is Rewoquat (e.g. Jarachowska et al., 2013), the trade name for a tenside (organic detergent; Kennedy and Coe, 2014) that has been used to disaggregate both organic-rich (Jarachowska et al., 

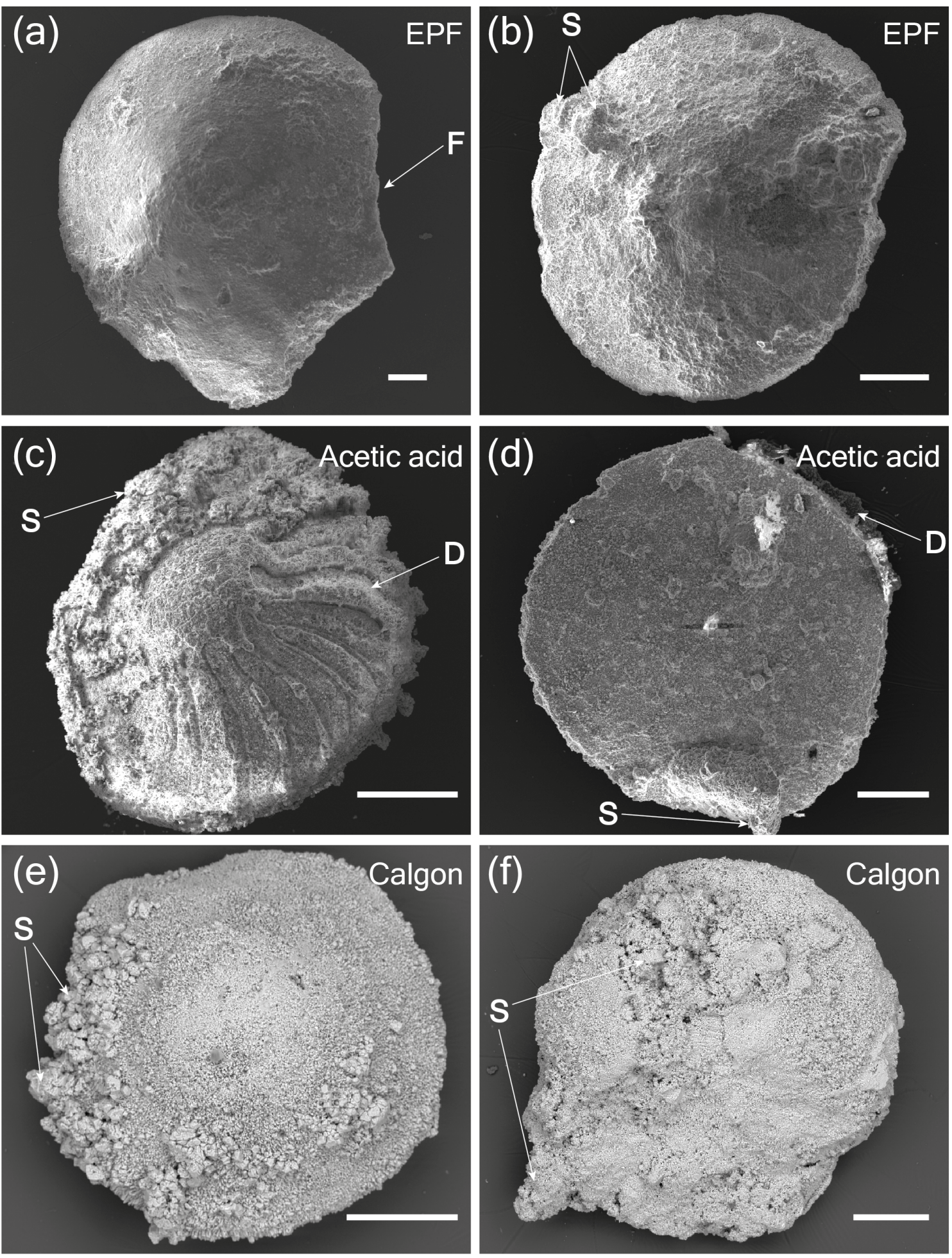

Figure 7. SEM and reflected light microscope images of select larger foraminifera from samples to show differential preservation from each technique. SE means that the image was taken in secondary electron mode. BSE means that the image was taken in backscattered electron mode. (a) K05 processed using EPF (SE) where some fragmentation (breakage) of specimen has occurred. (b) LCL processed using EPF (SE) where small amounts of sediment remain attached to the test surface. (c) K05 processed using acetic acid (SE) where dissolution has caused exposure of the internal chamber walls. (d) LCL processed using acetic acid (SE) where dissolution degraded the periphery of the test. (e) K05 processed using Calgon (BSE) where clumps of sediment remain attached to the test surface. (f) LCL processed using Calgon (BSE) where the test surface is obscured by large amounts of sediment remaining attached to the surface. Scale bars are $200 \mu \mathrm{m}$. S signifies sediment remaining attached to test surface, D signifies dissolution of the test surface and F signifies fragmentation of the specimen. 
Table 4. Comparison of sample properties and relative success with different disaggregation techniques.

\begin{tabular}{|c|c|c|c|c|c|}
\hline \multirow[t]{2}{*}{$\begin{array}{l}\text { Sample } \\
\text { name }\end{array}$} & \multirow[t]{2}{*}{ Cement or infilling } & \multirow[t]{2}{*}{$\begin{array}{r}\text { Average } \\
\text { size of clasts }\end{array}$} & \multicolumn{3}{|c|}{$\begin{array}{c}\text { Which disaggregation method } \\
\text { was effective? }\end{array}$} \\
\hline & & & EPF & Acetic acid & Calgon \\
\hline K05 & Quartz grains and clays & $>500 \mu \mathrm{m}$ & $\checkmark$ & $\checkmark$ & $x$ \\
\hline K09 & Clays and small amount of quartz grains & $>500 \mu \mathrm{m}$ & $\checkmark$ & $\checkmark$ & $\times$ \\
\hline K16 & Clays and quartz grains & $1-2 \mathrm{~mm}$ & $x$ & $x$ & $x$ \\
\hline L05 & Calcite and thin clays around pores & $>1000 \mu \mathrm{m}$ & $\checkmark$ & $x$ & $x$ \\
\hline LCL & Quartz grains and clays, calcitic crusts & $>1000 \mu \mathrm{m}$ & $\checkmark$ & $\checkmark$ & $x$ \\
\hline JB1 & Coarse-grained calcite & $<400 \mu \mathrm{m}$ & $x$ & $\times$ & $x$ \\
\hline JB3 & Fine-grained calcite & $<500 \mu \mathrm{m}$ & $x$ & $x$ & $x$ \\
\hline JF2 & Coarse-grained calcite & $\sim 50-300 \mu \mathrm{m}$ & $x$ & $x$ & $x$ \\
\hline JH1 & Fine-grained calcite & $200-500 \mu \mathrm{m}$ & $\checkmark$ & $\times$ & $x$ \\
\hline
\end{tabular}

2013; Kennedy and Coe, 2014) and carbonate lithologies (Wolfgring and Wagreich, 2016). As with the Calgon and acetic acid techniques analysed in this paper, the Rewoquat method requires repeated rounds of processing (multiple days) for more indurated samples, with additional soaking and/or washing with hydrogen peroxide (Kennedy and Coe, 2014). The extended periods of exposure to acids and/or surfactants required with many of these techniques risks dissolution or poor preservation of recovered fossil material.

Results of this study show that, in general, the EPF method disaggregated most samples the most effectively and efficiently; this method overall gave the highest LF recoveries compared to the acetic acid and Calgon methods (Figs. 5 and 6), whilst also liberating the best-preserved specimens (Fig. 7). Only samples K05 and JH1 yielded higher LF recoveries with the acetic acid method (Fig. 5); however, these samples were also successfully disaggregated using EPF with significantly less damage to the fossils. The EPF treatment time varied between 10 and $30 \mathrm{~s}$ per sample (Table 3); however, the stepwise processing method, including inspection between cycles and cleaning, resulted in an overall processing time of around $20 \mathrm{~min}$ per sample disaggregation, compared to Calgon and acetic acid that both required multiple days.

Samples that disaggregated well with EPF contained larger (> $500 \mu \mathrm{m}$ ) bioclasts (e.g. K05, K09, LCL, L05; Figs. 5 and 6). This method was effective regardless of the cement or matrix material, as samples containing calcitic, silicic, and clay matrix or diagenetic cements were disaggregated using EPF. Furthermore, Saini-Eidukat and Weiblen (1996) previously disaggregated sandstone and shale lithologies using EPF, obtaining a diverse assemblage of well-preserved microfossil moulds such as conodonts, foraminifera, fish teeth and am- monitella. This suggests EPF is a very broadly applicable method of disaggregation in micropalaeontology.

The only sample which did not fit with the above parameters is sample K16 (LF packstone-grainstone), which contained large bioclasts $(\sim 1-2 \mathrm{~mm})$ and a clay matrix containing quartz grains but was not disaggregated using any method (Table 4). We hypothesise that the bioclastic material was packed too closely together (Figs. 2a and 3c), therefore there was less cement or matrix for the disaggregation techniques to be effective on. More specifically, the EPF method was not effective on this sample, as a lack of matrix-LF boundaries reduces the contrast in electrical permittivity and conductivity between bioclasts, limiting internal boundaries upon which local shearing and thus fragmentation can be focussed.

Where these larger bioclasts $(>500 \mu \mathrm{m})$ were surrounded by a mixture of a quartz grains and clay matrix, acetic acid was also effective in disaggregating the samples (Table 4). We suggest that acetic acid was able to work in these cases due to the higher surface area that the fine-grained clays enabled the acid to work on. However, when acetic acid disaggregation was effective, the preservation of liberated material was compromised, which reduces the utility of the microfossils for further study (Fig. 7).

None of the tested methods were effective at liberating fossiliferous material from samples that contained small $(<500 \mu \mathrm{m})$ bioclasts such as planktic foraminifera or smaller benthic foraminifera (Table 4). We propose that future work to tailor the EPF method for use with smaller bioclasts could include the use of smaller sieve apertures and a greater number of processing rounds in which progressively smaller microfossil material could be collected. This would require the picking of already liberated microfossils between each processing round, increasing the time spent (and thus decreasing efficiency) but could ultimately improve the recoveries 
of smaller bioclasts. The EPF method could also be used as a pre-treatment step for other disaggregation techniques, such as acetic acid, where fractures generated from the process enhance permeability and thus acid penetration, which may reduce the amount of time that the samples need to be immersed in the corrosive liquid and hence improve preservation. In comparison to manually breaking up bulk material, the EPF method is far less likely to fragment microfossils prior to liberation due to it acting discriminately upon phase boundaries.

In terms of a best-practice methodology for implementing EPF on indurated microfossiliferous carbonates, we suggest the following: microfossils should be $500 \mu \mathrm{m}$ or larger; individual microfossils should not be touching, i.e. separated by matrix or cement; the composition of the matrix or cement is unimportant and can be fine or coarse grained and made up of calcareous, siliceous, or clay components. We propose that this technique can be used on a range of microfossil material with high specimen yields, good preservation and a short processing time. For the recovery of smaller microfossils $(<500 \mu \mathrm{m})$, repeated rounds of EPF processing with a gradually decreasing sieve aperture and picking of liberated material between rounds could improve recoveries, with the sacrifice of a less efficient methodology, although this remains to be experimentally tested.

\section{Conclusions}

The EPF method is highly efficient and effective as a disaggregation technique for liberating larger microfossils $(>500 \mu \mathrm{m})$ from indurated carbonate-rich sedimentary rocks. This method indiscriminately disaggregated indurated carbonates with a mixture of calcitic, silicic, and clay matrices and cements; it has also previously been shown to liberate microfossils from sandstones and shales (Saini-Eidukat and Weiblen, 1996), showing it to be a broadly applicable method to micropalaeontology. We further suggest that the EPF method could be tailored to effectively liberate smaller $(<500 \mu \mathrm{m})$ microfossils by using repeated rounds of processing and progressively smaller sieve aperture sizes, although further investigation is required.

Compared to the traditional methods of disaggregation, soaking in Calgon and acetic acid, the time required is significantly reduced and the preservation of liberated material is excellent. Acetic acid proved effective in some highly lithified samples; however, the time taken to process the samples is significantly longer and LF preservation was compromised. Calgon was unable to disaggregate any of the carbonate samples successfully (i.e. few or no LF were liberated) and thus is unsuitable for processing these highly lithified sedimentary rocks.

Data availability. Data will be available from PANGAEA in the future but remain unavailable at time of publishing.
Author contributions. $\mathrm{CB}$ conducted acetic acid and Calgon treatments, and DBP performed EPF treatment. CB picked and analysed all samples using thin sections and EDS-SEM. LC and CB provided sample material. $\mathrm{CB}$ constructed the manuscript with contributions from DBP, KL and LC.

Competing interests. Author Daniel B. Parvaz previously worked for SELFRAG AG, who donated staff time (Daniel B. Parvaz) and machine access to perform the EPF treatment for this article.

Acknowledgements. We would like to thank SELFRAG for the processing of the samples. We also thank Steve Pendray for preparing petrological thin sections and Calum Beeson for assistance with SEM-EDS analysis. Antonino Briguglio and another anonymous reviewer are thanked for their constructive reviews, which helped to significantly improve the manuscript. The research contained in this publication contains work conducted during CB's $\mathrm{PhD}$ programme undertaken as part of the Natural Environment Research Council (NERC) Centre for Doctoral Training in Oil and Gas and is fully funded by NERC, whose support is gratefully acknowledged.

Financial support. This research has been supported by the Natural Environment Research Council Centre for Doctoral Training in Oil and Gas (grant no. NE/M00578X/1).

Review statement. This paper was edited by Kirsty Edgar and reviewed by Antonino Briguglio and one anonymous referee.

\section{References}

Abdelghany, O.: Biostratigraphy (Turborotalia cunialensis/Cribrohantkenina inflata Concurrent-Range Zone, P16) of the Late Eocene Dammam Formation, west of the Northern Oman Mountains, Micropaleontology, 48, 209-221, 2002.

Abdelghany, O. and Abu Saima, M. M.: Stratigraphy of the Early Paleogene Muthaymimah Formation exposed on the western flank of the Northern Oman Mountains, Hist. Biol., 25, 629-642, https://doi.org/10.1080/08912963.2012.729830, 2013.

Andres, U., Jirestig, J., and Timoshkin, I.: Liberation of minerals by high-voltage electrical pulses, Powder Technol., 104, 37-49, https://doi.org/10.1016/S0032-5910(99)00024-8, 1999.

Andres, U., Timoshkin, I., Jirestig, J., and Stallknecht, H.: Liberation of valuable inclusions in ores and slags by electrical pulses, Powder Technol., 114, 40-50, https://doi.org/10.1016/S00325910(00)00260-6, 2001.

Barnet, J. S. K., Littler, K., Westerhold, T., Kroon, D., Leng, M. J., Bailey, I., Röhl, U., and Zachos, J. C.: A high-fidelity benthic stable isotope record of late Cretaceous-early Eocene climate change and carbon-cycling, Paleoceanogr. Paleocl., 34, 120, https://doi.org/10.1029/2019PA003556, 2019.

Bluhm, H., Frey, W., Giese, H., Hoppé, P., Schulteiss, C., and Strässner, R.: Application of pulses HV discharges to material 
fragmentation and recycling, IEEE Trans. Dieletr. Electr. Insul., 7, 625-636, 2000.

Bru, K., Touzé, S., and Parvaz, D. B.: Development of an innovative process for the upcycling of concrete waste, abstract no. 12, HISER conference, Delft, The Netherlands, 21-23 June 2017, ISBN/EAN: 978-94-6186-826-8, TU Delft Library, 2017.

Bru, K., Touzé, S., Auger, P., Dobrusky, S., Tierrie, J., and Parvaz, D. B.: Investigation of lab and pilot scale electric-pulse fragmentation systems for the recycling of ultra-high performance fibre-reinforced concrete, Miner. Eng., 128, 187-194, https://doi.org/10.1016/j.mineng.2018.08.040, 2018.

Bru, K., Sousa, R., Machado Leite, M., Broadbent, C., Stuart, G., Pashkevich, D., Martin, M., Kern, M., and Parvaz, D. B.: Pilot-scale investigation of two Electric Pulse Fragmentation (EPF) approaches for the mineral processing of a low-grade cassiterite schist ore, Miner. Eng., 150, 106270, https://doi.org/10.1016/j.mineng.2020.106270, 2020.

Costa de Moura, J., de Moraes Rios-Netto, A., Wanderley, M. D., and Pereira de Sousa, F.: Using acids to extract calcareous microfossils from carbonate rocks, Micropalaeontology, 45, 429-436, 1999.

Cotton, L. J.: Paleogene larger benthic foraminifera of Tanzania and the Eocene-Oligocene transition, $\mathrm{PhD}$ thesis, Cardiff University, UK, 162 pp., 2012.

Dal Martello, E., Bernardis, S., Larsen, R. B., Tranell, G., Di Sabatino, M., and Arnberg, L.: Electrical fragmentation as a novel route for the refinement of quartz raw materials for trace mineral impurities, Powder Technol., 224, 209-216, 2012.

D'Onofrio, R. and Luciani, V.: Do different extraction techniques impact planktic foraminiferal assemblages? An early Eocene case study, Mar. Micropalaeontol., 155, 101795, https://doi.org/10.1016/j.marmicro.2019.101795, 2020.

Falzoni, F., Petrizzo, M. R., Jenkyns, H. C., Gale, A. S., and Tsikos, H.: Planktic foraminiferal biostratigraphy and assemblage composition across the Cenomanian-Turonian boundary interval at Clot Chevalier (Vocontian Basin, SE France), Cretaceous Res., 59, 69-97, https://doi.org/10.1016/j.cretres.2015.10.028, 2016.

Hodgkinson, R. L.: Microfossil processing: A damage report, Micropalaeontology, 37, 320-326, 1991.

Jarachowska, E., Tonarová, P., Minnecke, A., Ferrová, L., Sklenár̆, J., and Vodrážková, S.: An acid-free method of microfossil extraction from clay-rich lithologies using the surfactant Rewoquat, Palaeontol. Electron., 16, 1-16, 2013.

Jovane, L., Florindo, F., Coccioni, R., Dirarès-Turell, J., Marsili, A., Monechi, S., Roberts, A. P., and Sprovieri, M.: The middle Eocene climatic optimum event in the Contessa Highway section, Umbrian Apennines, Italy, Geol. Soc. Am. Bull., 119, 413427, https://doi.org/10.1130/B25917.1, 2007.
Kennedy, A. E. and Coe, A. L.: Development of the freeze-thaw processing technique for disaggregation of indurated mudrocks and enhanced recovery of calcareous microfossils, J. Micropalaeontol., 33, 193-203, https://doi.org/10.1144/jmpaleo2013-020, 2014.

Lirer, F.: A new technique for retrieving calcareous microfossils from lithified lime deposits, Micropaleontology, 46, 365-369, 2000 .

Nicholas, C. J., Pearson, P. N., Bown, P. R., Dunkley Jones, T., Huber, B. T., Karega, A., Lees, J. A., McMillan, I. K., O'Halloran, A., Singano, J. M., and Wade, B. S.: Stratigraphy and sedimentology of the Upper Cretaceous to Paleogene Kilwa Group, southern coastal Tanzania, J. Afr. Earth Sci., 45, 431-466, 2006.

Nolan, S. C., Skelton, P. W., Clissold, B. P., and Smewing, J. D.: Maastrichtian to early Tertiary stratigraphy and palaeogeography of the Central and Northern Oman Mountains, in: The Geology and Tectonics of the Oman Region, edited by: Searle, A. H. F. and Ries, M. P., Geol. Soc. Sp., 49, 495-519, 1990.

Parvaz, D. B., Beasley, C., and Littler, K.: Recovery of intact foraminifera from indurated host rock by electric pulse fragmentation, Sample Preparation Using High Voltage Electrical Pulses, Poster, https://doi.org/10.13140/RG.2.2.24194.17602, 2018.

Pedley, H. M.: The Oligo-Miocene sediments of the Maltese islands, PhD thesis, University of Hull, UK, 205 pp., 1975.

Renema, W. and Cotton, L.: Three dimensional reconstructions of Nummulites tests reveal complex chamber shapes, PeerJ, 3 , e1072, https://doi.org/10.7717/peerj.1072, 2015.

Riding, J. B. and Kyffin-Hughes, J. E.: A review of the laboratory preparation of palynomorphs with a description of an effective non-acid technique, Rev. Bras. Paleontolog., 7, 13-44, 2004.

Saini-Eidukat, B. and Weiblen, P. W.: A new method of fossil preparation, using high-voltage electric pulses, Curator, 39, 139-144, 1996.

SELFRAG AG: Lab v. 2.0 User Manual, Document SELFRAG Lab, SELFRAG AG, Kerzers, Switzerland, 2012.

van der Wielen, K. P.: Application of high voltage breakage to a range of rock types of varying physical properties, $\mathrm{PhD}$ thesis, Camborne School of Mines, University of Exeter, UK, 2013.

Wang, E., Shi, F., and Manlapig, E.: Mineral liberation by high voltage pulses and conventional comminution with same specific energy levels, Miner. Eng., 27, 28-36, 2012.

Wolfgring, E. and Wagreich, M.: A quantitative look on northwestern Tethyan foraminiferal assemblages, Campanian Nierental Formation, Austria, PeerJ, 4, e1757, https://doi.org/10.7717/peerj.1757, 2016. 